\title{
PROTOTIPE PENDETEKSI KANDUNGAN ZAT METANA UNTUK PEMBUDIDAYAAN JAMUR TIRAM BERBASIS MIKROKONTROLLER ARDUINO
}

\author{
Diah Aryani ${ }^{1}$ \\ Fanida Yantiar ${ }^{2}$ \\ Muhammad Husni Farid ${ }^{3}$

\begin{abstract}
Dosen STMIK Raharja Tangerang ${ }^{1}$, Mahasiswa STMIK Raharja Tangerang ${ }^{2,3}$
Jl. Jendral Sudirman No.40, Modernland, Tangerang 1,2,3
\end{abstract} \\ email: diah.aryani@ raharja.info ${ }^{1}$, fanida@ raharja.info ${ }^{2}$, husni@ raharja.info ${ }^{3}$
}

\begin{abstract}
ABSTRAK
Jamur tiram (pleurotus ostreatus) adalah jamur pangan dari kelompok Basidiomycota dan termasuk kelas Homobasidiomycetes dengan ciri-ciri umum tumbuh buah berwarna putih hingga krem dan tudungnya berbebtuk setengah lingkaran mirip dengan cangkang tiram dengan bagian tengah aga jekung .Jamur tiram ini masih satu kerabat dengan pleurotus eryngii dan sering dikenal dengan sebutan kingh oyster Mushoom. Banyak pembudidaya jamur tiram yang masih kesulitan dalam proses budidaya jamur tiram itu sendiri. Selain faktor iklim \& cuaca, keadaan lingkungan sekitar juga dapat mempengaruhi pertumbuhan jamur tiram. Dengan kemajuan di bidang komunikasi dan mikrokontroller Arduino saat ini, para pembudidaya jamur tiram dapat menggunakannya sebagai media bantu pertumbuhan jamur tiram. Dengan bantuan sensor suhu, sensor soil moisture dan sensor gas MQ-2. Maka hal ini bukan lagi mustahil. Kondisi tanah, suhu cuaca \& kandungan zat metana yang terdapat didalam tanah, bisa dipantau melalui satu alat saja. Sehingga alat ini dapat membantu para pembudidaya jamur tiram supaya dapat menghasilkan jamur tiram dengan kualitas unggul.
\end{abstract}

Kata Kunci: Jamur Tiram, Arduino

ABSTRACT

Oyster mushroom (Pleurotus ostreatus) is an edible mushroom from the group Basidiomycota and including Homobasidiomycetes class with common characteristics of fruit grown white to beige and hood berbebtuk semicircle similar to oyster shells with the middle aga jekung. Jamur oyster is still a relative with Pleurotus eryngii and commonly known as oyster kingh Mushoom. Many farmers are still having trouble oyster mushrooms in oyster mushroom cultivation process itself. In addition to climatic factors and weather, the state of the environment can also affect the growth of oyster mushrooms. With the advancement in the field of communication and Arduino microcontroller today, the oyster mushroom farmers can use it as auxiliary media of oyster mushroom growth. With the aid of temperature sensors, soil moisture sensors and gas sensors MQ-2. Then it is no longer impossible. Soil conditions, weather temperature and methane content of substances contained in the soil, can be monitored through a single device. So that this tool can help farmers in order to produce oyster mushroom oyster mushrooms with superior quality.

Keywords: Oyster Mushrooms, Arduino 


\section{PENDAHULUAN}

Jamur tiram merupakan salah satu tanaman berprotein tinggi yang hanya dapat hidup di daerah dataran tinggi yang banyak di budidayakan oleh para petani. Sehingga produksi jamur hanya menghasilkan kurang lebih 50 sampai $100 \mathrm{~kg}$ per kumpung tiap harinya.Seiring berkembangnya jaman dan teknologi,maka pada masa kini juga sebagian besar pembudidayaan jamur tiram dilakukan oleh tenaga manusia dengan sistem industri rumahan yang kelembaban ruang budidaya jamur tiramnya dapat disesuaikan dengan daearah dataran rendah.Pertumbuhan jamur tiram sangat tergantung pada faktor fisik seperti suhu,kelembaban,cahanya dan PH media tanah kondisi tersebut adalah nilai kelembaban yang ideal dan seimbang,terlalu basah atau kering kurang baik bagi kelangsungan hidup jamur tiram tersebut.Keberhasilan yang terjadi dalam sistem budidaya jamur akan tercapai apabila diketahui zat methane pada tanah. Maka dari itulah dibutuhkan alat yang mampu memantau perubahan suhu dan kondisi tanah pada jamur tiram.

Seiring juga dengan perkembangan IPTEK, peralatan elektronik seperti komputer, internet yang sudah sangat pesat di kalangan masyarakat. Sehingga banyak sekali produk elektronik dengan inovasi tinggi. Dan banyak juga yang memanfaatkan teknologi IT untuk membantu manusia dalam membudidayakan tanaman.Arduino yang merupakan pengembangan dari mikrokontroller Atmega328, dirancang agar mudah digunakan diberbagai bidang elektronik. Faktor iniliah yag membuat arduino cukup populer diberbagai belahan dunia.

Dengan alasan inilah penulis ingin mencari sebuah solusi agar sistem komputerisasi bisa diterapkan dengan menggabungkan komponen arduino dengan beberapa perangkat sensor. Sehingga dapat digunakan sebagai perangkat monitoring zat metana pada jamur tiram.

Untuk permasalahan tersebut, maka penulis mengembangkan suatu alat yang disebut dengan sistem pendeteksi zat metana untuk tanah pembudidayaan pada tanaman jamur tiram untuk pengembangan kulitas dan kuantitas jamur.

\section{LANDASAN TEORI}

\section{Literature Review}

Dalam upaya perlu dilakukan studi pustaka sebagai salah satu dari penerapan metode penelitian yang akan dilakukan. Diantaranya adalah mengidentifikasikan kesenjangan (identify gaps), menghindari pembuatan ulang (reinventing the wheel), mengidentifikasikan metode yang pernah dilakukan, serta mengetahui orang lain yang spesialisasi dan area penelitian yang sama dibidang ini. Beberapa Literature Review tersebut adalah sebagai berikut :

1. Penelitian yang telah dilakukan oleh Luvia Giantika [2015] dari STMIK Raharja dengan judul "PROTOTIPE PENYIRAM TANAMAN BERBASIS RASPBERRY PI MELALUI TWITTER PADA PT. DIAN SURYA GLOBAL". Pada KKP ini bertujuan membuat suatu media penyiram tanaman melalui twitter.

2. Penelitian yang dilakukan oleh Linda Romaito Has dari dari Universitas Sumatra Utara ${ }^{[3]}$,sebagai bentuk tugas akhir skripsi dengan judul "PERANCANGAN ALAT PENGONTROL PENYIRAMAN OTOMATIS BERBASIS MIKROKONTROLER AT89S52 PADA TANAMAN STROBERI". Pada tugas akhir skripsi ini penulis menggunakan perangkat lunak mikrokontroler AT89S52. Dimana mikrokontroler ini merupakan otak dari semua sistem yang ada pada rancangan ini. Alat pengontrolan penyiraman ini mempunyai prinsip kerja yaitu : sensor kebasahan tanah menggunakan empa tbuah probe tembaga yang ditanamkan. 
3. Penelitian ini dilakukan oleh Mohamad dari Politeknik Negeri Bandung [4],sebagai bentuk Tugas Akhir Skripsi dengan judul "SISTEM PENYIRAMAN TANAMAN JAMUR TIRAM OTOMATIS BERBASIS MIKROKONTROLLER ATMEGA32". Padatugas akhir skripsi ini penulis IC Real Time Clock (RTC) DS1307 berfungsi sebagai timer untuk mengatur waktu penyiraman, dan data ini akan disimpan dalam EEPROM mikrokontroler ATmega32. Sistem kerja alat menggunakan motor dc untuk menggerakkan alat penyiram tanamannya.

4. Penelitian yang telah dilakukan oleh Egi Wahyu Rachmat dari STMIK RAHARJA ${ }^{[6}$. sebagi bentuk Kuliah Kerja Praktek dengan judul "ALAT PENYIRAMAN TANAMAN OTOMATIS BERBASIS ARDUINO". Pada tugas kuliah kerja praktek ini penulis bertujuan untuk menggabungkan beberapa komponen mikrokontroller dan pemanfataan system embeddes yang dapat digunakan untuk gedung perkantoran yang belum dilengkapi dengan camera atau sms gateway sebagai media interface nya.

Dari empat Literature review yang ada, telah banyak penelitian mengenai penyiraman tanaman, alat penyiram otomatis, mikrokontoler, sensor tanah, Arduinodan Media Wireless. Di samping itu juga ada pembahasan mengenai perancangan beberapa alat penyiram tanaman yaitu Pengendalian Alat Penyiraman dan Pemupukan Tanaman Menggunakan Smartphone Arduino Melalui Media Wireless. Namun dapat disimpulkan pula bahwa belum ada peneliti yang secara khusus membahas mengenai perancanga nalat pengukur zat metana, yang menggunakan arduinosebagai media pemrosesannya.

\section{Arduino Uno}

Menurut Abdul Kadir(2015:2), “Arduino adalah nama keluarga papan mikrokontroller yang awanya dibuat oleh buat oleh perusahaan Smart Project salah satu tokoh penciptanya adalah Massimo Banzi. Papan ini merupakan perangakat keras yang bersifat "open souce" sehingga boleh dibuat oleh saja."

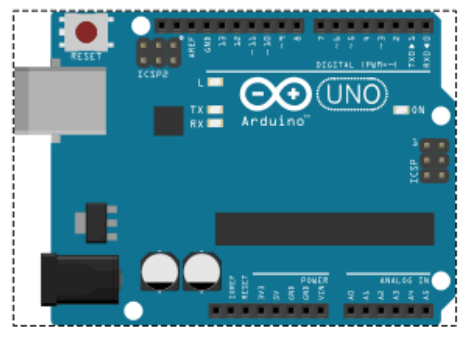

Gambar 2. MikrokontrollerArduino Uno

Seperti yang tertera pada situs resmi Arduino, yaitu www.arduino.cc. Arduino dapat diberikan power melalui koneksi USB atau power supply.Powernya menyala secara otomatis. Power supply dapat menggunakan adaptor DC atau baterai. Adaptor dapat dikoneksikan dengan mencolok jack adaptor pada koneksi port input supply. Board arduino dapat dioperasikan menggunakan supply dariluarsebesar 6 - 20 volt. Jika supply kurang dari 7V, kadangkala pin $5 \mathrm{~V}$ akan menyuplai kurang dari 5 volt dan board bisa menjadi tidak stabil. Jika menggunakan lebih dari $12 \mathrm{~V}$, tegangan di regulator bisa menjadi sangat panas dan menyebabkan kerusakan pada board. Rekomendasi tegangan ada pada 7 sampai 12 volt. Arduino sendiri memiliki IDE untuk compiler. Proses kerja Arduino ialah melakukan pemrograman pada IDE, compile, dan upload binary/hex file kekontroler.Berbedadenganprocessing yang kodehasil compile langsung dijalankan di komputer, kodehasil compile Arduino harus diupload kekontroler sehingga dapat dijalankan. Fungsi tombol pada IDE Arduino: 
Verify : Cek error dan lakukan kompilasi kode.

Upload : Upload kode ke board/kontroler. Asumsi bahwa board dan serial port telah disetting dengan benar.

New : Membuat aplikasi baru.

Open : Buka proyek yang telah ada atau dari contoh-contoh/examples.

Save : Simpan proyek anda. Serial Monitor: Membuka serial portmonitor untuk melihat feedback/umpan balik dari board.

\section{Sensor Asap MQ-2}

Sensor gas asap MQ-2 ini mampu mendeteksi konsentrasi gas yang mudah terbakar di udara serta asap dan outputmembaca sebagai tegangan analog. Sensor gas asap MQ-2 dapat langsung di atur sensitifitasnya dengan memutar trimpot.Sensor ini biasanya digunakan untuk mendeteksi kebogoran gas baik di rumah maupun di industry .Gas yang dapat di deteksi diantaranya :LPG,i-butane,propane,methane,alcohol,hydrogen, smoke.Sensor ini dapat mendeteksi konsentrasi gas yang mudah terbakar di udara serta asap dan keluarannya berupa tegangan analog.Sensor ini dapat mengukur kobsentrasi gas mudah terbakar dari 300 sampai 10.000sensor ppm.Dapat beroprasi pada suhu $20^{\circ} \mathrm{C}$ sampai $50^{\circ} \mathrm{C}$ dan menkonsumsi arus kurang dari 150 Ma pada $5 \mathrm{~V}$.

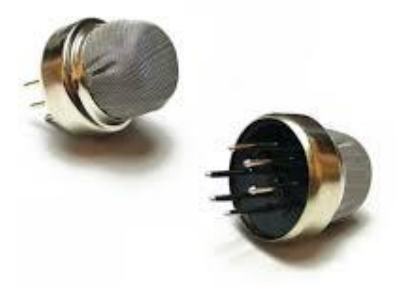

Gambar 3. Sensor asap MQ-2

(Sumber : Datasheet MQ-2)

\section{Sensor Soil Moisture}

Menurut datasheet dari Soil Moisture Sensor, merupakan sensor yang mampu mendeteksi intensitas air di dalam tanah. Sensor ini berupa dua buah paku konduktor berbahan logam yang sangat sensitif terhadap muatan listrik. Kedua paku ini merupakan media yang akan menghantarkan tegangan analog yang nilainya relatif kecil. Tegangan ini nantinya akan diubah menjadi tegangan digital untuk diproses ke dalam mikrokontroler. Soil Moisture Sensor menggunakan LM393 chip Power supply : 3.3V atau 5V. Sensor ini terdiri dua probe untuk melewatkan arus melalui tanah, kemudian membaca resistansinya untuk mendapatkan nilai tingkat kelembaban. Semakin banyak air membuat tanah lebih mudah menghantarkan listrik (resistansi kecil), sedangkan tanah yang kering sangat sulit menghantarkan listrik (resistansi besar). 


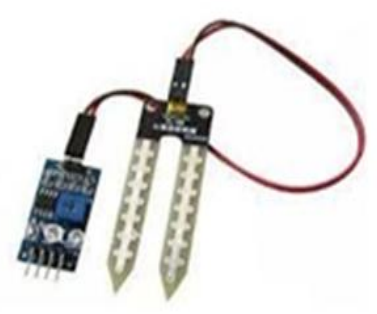

Gambar 4. Sensor Soil Moisture

(Sumber : Datasheet Sensor Soil Moisture)

\section{4. $\quad$ Sensor Suhu LM35}

Menurut datasheet dari sensor suhu LM35, sensor LM35merupakan perangkat temperature IC yang presisi dengan voltage output linear-proporsional ke temperature centigrade. Perangkat LM35 memiliki kelebihan pada sensor temperature linearyang terkalibrasi dalam satuan kelvin. LM35 tidak memerlukan pengaturan tambahan. (sumber : Datasheet sensor LM35)

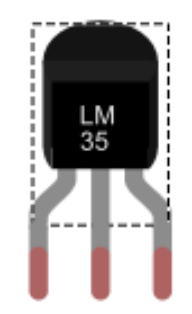

Gambar 5. Sensor suhu LM35

( Sumber : Datasheet LM35 )

\section{Listing Program}

Perancangan perangkat lunak, adalah melakukan penulisan listing program ke dalam suatu Software Arduino 1.0.5 dengan menggunakan bahasa pemrograman C, dimana perintah-perintah program tersebut akan di eksekusi oleh hardware atau sistem yang di buat. Berikut ini adalah listing program yang digunakan.

\#include <LiquidCrystal.h>

LiquidCrystallcd(7, 6, 5, 4, 3, 2);

constintsensorgas $=A 1$;

constintsensorsoil $=A O$;

constintsensorsuhu=A2;

constintdigitalsensorsoil $=13$;

intvalsensorsoil $=0$;

intvalsensorasap $=0$;

intvalsensorsuhu $=0$;

floatcelsiussuhu $=0$;

intledhijau=8;

intledmerahgas $=9$;

intledmerahsoil $=10$;

intledmerahsuhu=11; 
int relay $=12$;

void setup ())

Serial.begin(9600);

lcd.begin (16, 2);

pinMode(ledhijau, OUTPUT);

pinMode(ledmerahgas, OUTPUT);

pinMode(ledmerahsoil, OUTPUT);

pinMode(ledmerahsuhu, OUTPUT);

pinMode(digitalsensorsoil, OUTPUT);

digitalWrite(digitalsensorsoil, LOW);

pinMode(relay, OUTPUT);

\}

void loop()

I

//@@@@@@@@@@@@@@@@@@@@@@@@@@@@@@@@@@@@@@@@ @@@@@@@@@@@@@@@@@@@@@@@

// SENSOR ASAP

valsensorasap $=$ analogRead $(0)$;

Serial.println(valsensorasap, DEC);

if(valsensorasap $>=320)$ \{

digitalWrite(ledhijau, LOW);

digitalWrite(relay, HIGH);

digitalWrite(ledmerahgas, $\mathrm{HIGH}$ );

delay(1000);

digitalWrite(ledmerahgas, $L O W)$;

delay(1000);

\}

I/\#\#\#\#\#\#\#\#\#\#\#\#\#\#\#\#\#\#\#\#\#\#\#\#\#\#\#\#\#\#\#\#\#\#\#\#\#\#\#\#\#\#\#\#\#\#\#\#\#\#\#\#\#\#\#\#

// SENSOR SUHU

getTemperature();

Serial.println(celsiussuhu);

delay(1000);

\}

voidgetTemperature()\{

valsensorsuhu $=$ analogRead $($ sensorsuhu $)$;

celsiussuhu $=($ valsensorsuhu $* 0.0065) * 100$;

// Serial.println(celsiussuhu);

lcd.clear();

lcd.setCursor $(0,0)$;

lcd.print(celsiussuhu);

// Serial.println(celsiussuhu);

lcd.print(" Temperature");

lcd.setCursor $(0,1)$;

lcd.print ((celsiussuhu * 9)/ $5+32)$;

lcd.print(" Kelembaban");

delay(1000); 
if (celsiussuhu $>=30)\{$

lcd.clear();

lcd.setCursor $(0,0)$;

lcd.print(celsiussuhu);

// Serial.println(celsiussuhu);

lcd.print(" Temperature");

lcd.setCursor $(0,1)$;

lcd.print ((celsiussuhu * 9)/ $5+32)$;

lcd.print(" Kelembaban");

delay(1000);

\}

//@@@@@@@@@@@@@@@@@@@@@@@@@@@@@@@@@@@@@@@@ @@@@@@@@@@@@@@@@@@@@@@

else\{

//digitalWrite(indsiram, HIGH);

// digitalWrite(indselesaisiram, LOW);

// digitalWrite(pompasiram, $\mathrm{LOW}$ );

lcd.clear();

lcd.setCursor $(0,0)$;

lcd.print(celsiussuhu);

// Serial.println(celsiussuhu);

lcd.print(" Temperature");

lcd.setCursor $(0,1)$;

lcd.print ((celsiussuhu* 9)/ $5+32)$;

lcd.print(" Kelembaban");

delay(1000);

\}

//@@@@@@@@@@@@@@@@@@@@@@@@@@@@@@@@@@@@@@@@ @@@@@@@@@@@@@@@@@@@@

digitalWrite(digitalsensorsoil, $\mathrm{HIGH})$;

delay(100);

valsensorsoil $=$ analogRead $($ sensorsoil $) ;$

digitalWrite(digitalsensorsoil, LOW);

delay(1000);

Serial.print("sensor = ");

Serial.println(valsensorsoil);

if $($ valsensorsoil $>=930)\{$ 
\}

//@@@@@@@@@@@@@@@@@@@@@@@@@@@@@@@@@@@@@@@@ @@@@@@@@@@@@@@@@@@@@@@

\}

\section{PERMASALAHAN}

Kebanyakan para pelaku budidaya jamur tiram masih menggunakan cara lama untuk mengetahui tingkat kesuburan tanah, sehingga jika terjadi perbuhan iklim dan cuaca maka akan mempengaruhi proses pertumbuhan jamur tiram. Tanah yang awal keliahatan subur bisa saja berubah karena faktor alam. Untuk itulah dibutuhkan suatu sistem kerja alat yang dapat membantu para pembudidaya jamur tiram untuk mendapatkan hasil yang maksimal.

Sehingga diusulkan sistem prototipe yang dapat mengetahui kandungan zat metana pada tanah dan Bagaimana cara menciptakan alat yang dapat mendukung pertumbuhan jamur tiram?.

\section{PEMBAHASAN}

\section{Diagram Blok Rangakain}

Rancangan

blok

diagram

dari

PrototipePendeteksiKandunganZatMetanaUntukPembudidayaanJamurTiramBerbasisMikrok ontrollerArduino menggunakan sensor asap MQ-2, sensor soil moisture dan sensor suhu LM35 sebagai media input data. LED, buzzer dan LCD digunakan sebagai media output data. Secara lengkap dapat dilihat pada gambar dibawah ini :

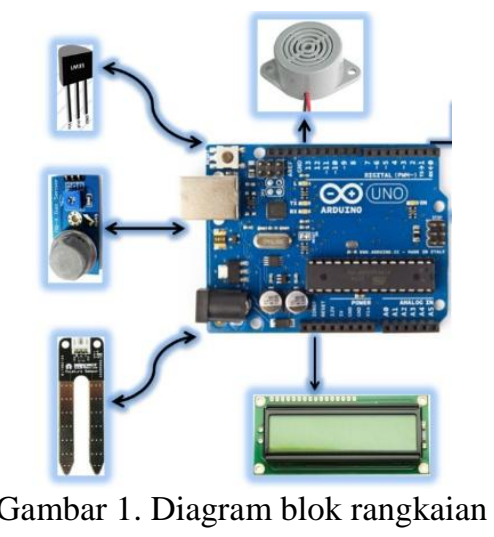

Keterangan dari gambar diagram blok diatas :

1. Seluruh sensor yang ada akan melakukan pengambilan data pada tanah yang akan di tanami jamur tiram

2. Data kemudian dikirimkan pada arduino, yang selanjutnya akan diproses.

3. Setelah data selesai diproses, kemudian data akan langsung ditampilkan pada lcd 16x2, sehingga user bisa langsung mengetahui kondisi tanah.

4. Buzzer akan aktif jika kondisi tanah tidak sesuai dengan standar yang telah ditentukan sistem.

\section{PERANCANGAN PROTOTIPE}

Dari semua sensor sebelumnya, kemudian semuanya dirangkai hingga setiap sensor dapat berkomunikasi dengan arduino dan prototipealatini dapat berjalan. 


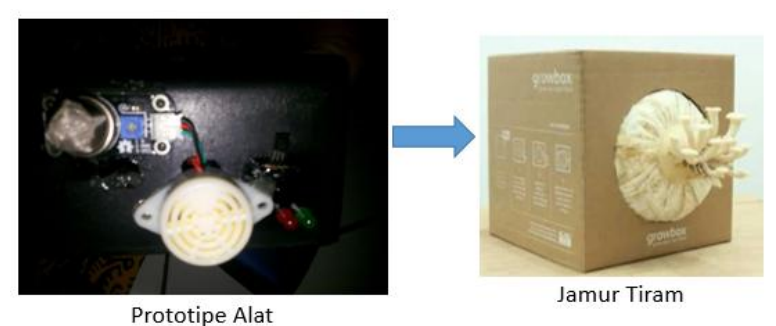

Gamabar 6. Prototipe Alat

\section{CARA KERJA ALAT}

Cara kerja alat ini adalah :

1. Saat alat dinyalakan seluruh sensor dan komponen langsung aktif dan siap mengambil data.

2. Sensor MQ-6 akan mengambil data mengenai kondisi udara, LM35 akan mengambil nilai suhu dan sensor Soil Moisture akan mengambil data mengenai kondisi tanah jamur tiram.

3. Data yang telah diambil melalui sensor akan langsung diproses oleh arduino.

4. Seluruh data yang telah selesai diproses akan ditampilkan pada layar LCD.

5. Jika dari ketiga sensor terdapat hal yang tidak sesuai atau berpotensi menggangu proses pertumbuhan jamur tiram maka buzzer akan aktif dan LCD akan menampilkan pesan peringatan.

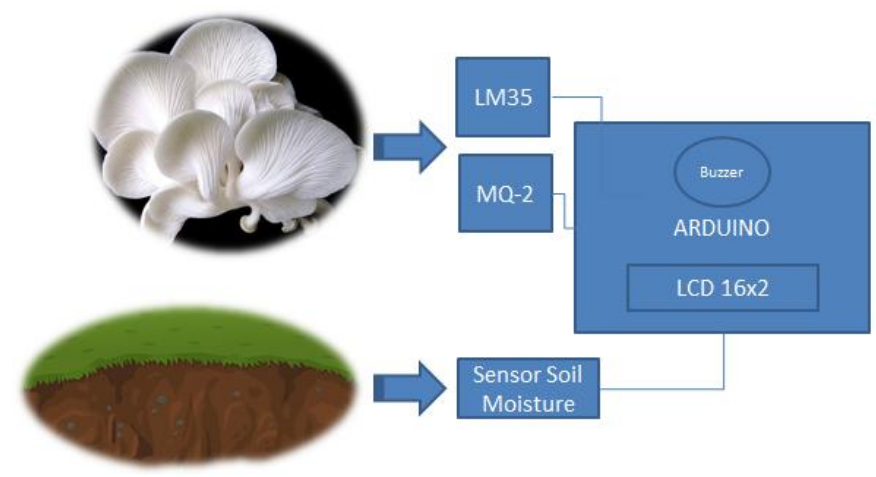

Gambar 7. Cara kerja alat

\section{KESIMPULAN}

Dari perancangan dan implementasi yang dilakukan maka dapat diperoleh kesimpulan sebagai berikut :

1. Prototipe alat ini berbasis arduino dengan menggunakan sensor-sensor suhu, kelembapan dan sensor yang dapat mendeteksi kandungan zat metana didalam tanah. Alat tersebut dapat mendukung pertumbuhan jamur dengan baik, karena alat tersebut dapat digunakan saat tanah didalam tanah terdapat kandungan zat metana.

2. Prototipe alat ini dibuat dengan menggunakan arduino sebagai sistem yang mampu mendeteksi kandungan zat metana dalam tanah sebagai media tanam budidaya jamur tiram. 


\section{DAFTAR PUSTAKA}

[1]. Adelia, dan Jimmy Setiawan. 2011. Implementasi Customer Relationship Management (CRM) pada Sistem Reservasi Hotel berbasisi Website dan Desktop. Bandung: Universitas Kristen Maranatha. Vol. 6, No. 2, September 2011:113-126.

[2].Al-Jufri, Hamid. 2011. Sistem Infromasi Manajemen Pendidikan. Jakarta: PT. Smart Grafika.

[3]. Darmawan, Deni. 2013. Sistem Informasi Manajemen. Bandung: PT. Remaja Rosdakarya Offset.

[4].Hartono,Bambang.2013. Sistem Informasi Manajemen Berbasis Komputer. Jakarta: PT . Rineka Cipta.

[5].Henderi, Maimunah, dan Randy Andrian. 2011. Desain Aplikasi E-learning Sebagai Media Pembelajaran Artificial Informatics. Tangerang: Jurnal CCIT. Vol. 4, No.3-Mei 2011.

[6].Herlawati. 2011. Menggunakan UML. Jakarta PT. Elex Media Komputindo.

[7]. Kadir, Abdul. 2015. "From Zero to a Pro". Yogyakarta: CV. Andi Offset.

[8].Rosa, A.S., dan M. Shalahuddin. 2013. Rekayasa Perangkat Lunak Terstruktur dan Berorientasi Objek. Bandung: Informatika.

[9].Siahaan, Daniel. 2012. Analisa Kebutuhan dalam Rekayasa Perangkat Lunak. Yogyakarta: CV. Andi Offset.

[10]. Sulindawati, dan Muhammad Fathoni. 2010. Pengantar Analisa Perancangan "Sistem". Medan: STMIK Triguna Dharma. Vol. 9, No. 2, Agustus 2010.

[11]. Sutabri, Tata. 2012. Konsep Sistem Informasi.Yogyakarta: CV . Andi Offset.

[12]. Taufiq, Rohmat. 2013. Sistem Informasi Manajemen. Yogyakarta: Graha Ilmu.

[13]. Yasin, Ferdi. 2012. Rekayasa Perangkat Lunak Berorientasi Objek. Jakarta: Mitra Wacana Media.

[14]. Yuliastrie, Nenden Dewi, Junaidi, Khanna Tiara. 2013. Sistem Pakar Monitoring Inventory Control Untuk Menghitung Harga Jual Efektif Dalam Meningkatkan Keuntungan. Yogyakarta: Universitas Ahmad Dahlan. 